\title{
SYSTEM OF TRANSCIPTION
}

Special attention should be applied to distinguishing the $b e^{\prime}(b)$ and the 'beth (cb), and representing the dagesh by double consonants (tiqqun and not tikun).

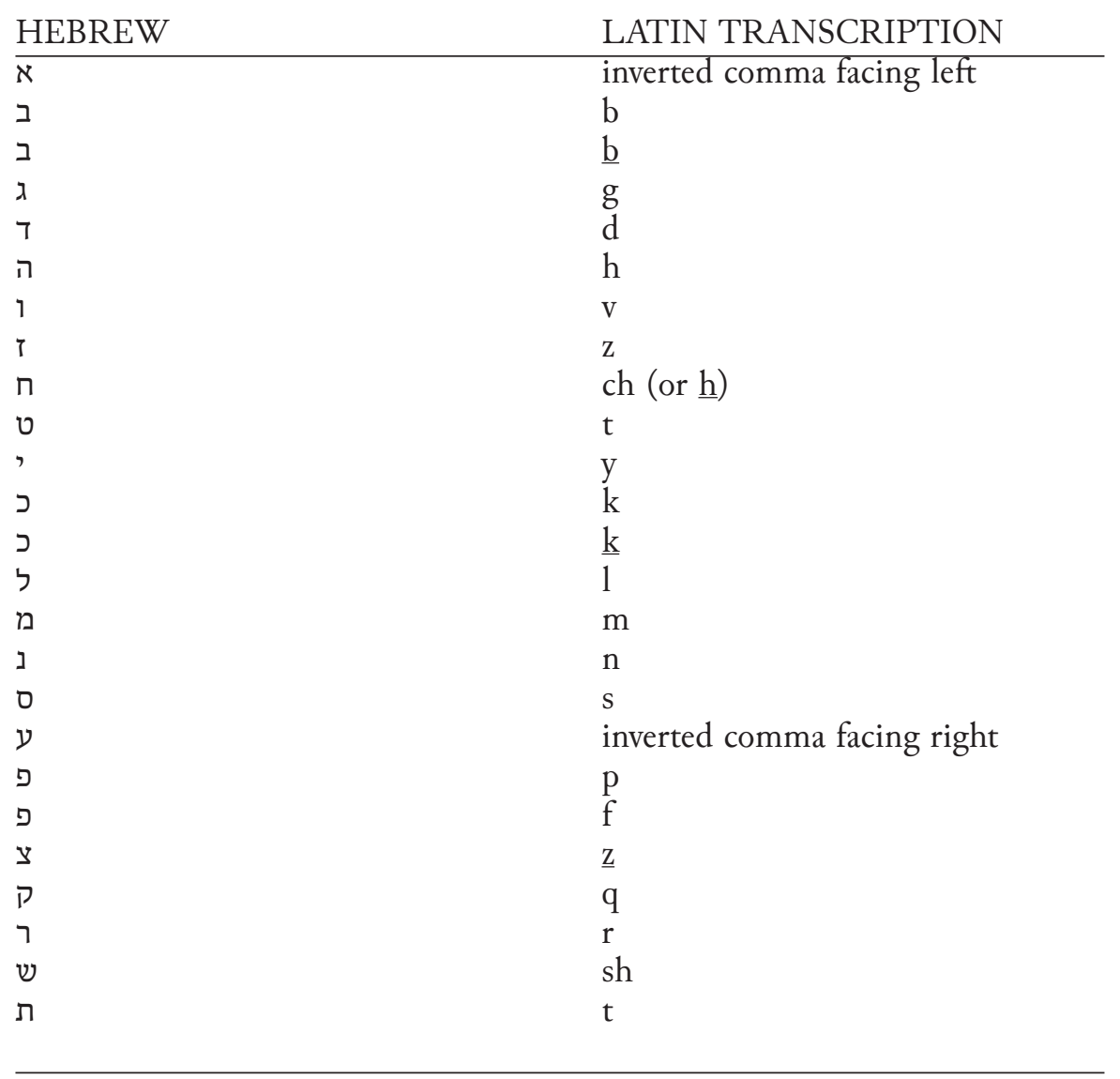

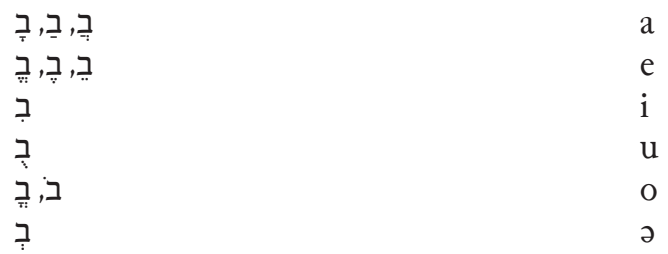


I would believe only in a God who could dance.

-Friedrich Nietzsche, Thus Spoke Zarathustra

... dance is governed by the perpetual renewal of the relation between vertigo and exactitude.

-Alain Badiou, Dance as a Metaphor for Thought 